\title{
Early Childhood Care and Education in Cambodia
}

\author{
Nirmala Rao \\ Veronica Pearson \\ The University of Hong Kong \\ Hong Kong, China
}

\begin{abstract}
This paper analyses child care and education policy in Cambodia, a country where there is currently a strong commitment to Early Childhood Care and Education (ECCE). This is done by (i) providing an overview of national statistics related to the health and development of young Cambodian children and information about their access to ECCE programs; (ii) considering government policy, administrative structures, and funding for ECCE; and (iii) discussing the different models of preschool provision (state preschools, community preschools, home-based programs and private preschools) that are available. Recent initiatives and research findings are discussed and the implications of the analysis for policy development and young children's well-being are considered.
\end{abstract}

Key words : early childhood care and education, policy, Cambodia

Cambodia has subscribed to the goals of the 2000 Education for All (EFA) Dakar Framework for Action and this paper focuses on issues related to its progress towards the first EFA goal, i.e., expanding and improving comprehensive early childhood care and education, especially for the most vulnerable and disadvantaged children. In the developing world, Early Childhood Care and Education (ECCE) adopts a holistic approach to the child, supporting children's survival, growth, development and learning. This includes health, nutrition and hygiene as well as cognitive, social, physical and emotional development - from birth to entry into primary school. ECCE programs involve a variety of locations and arrangements, from parenting programs to community

Correspondence concerning this article should be addressed to Nirmala Rao, Professor, Faculty of Education, The University of Hong Kong, Pok Fu Lam Road, Hong Kong, China. Electronic mail may be sent to nrao@hku.hk. based child care, center based provision and preprimary education in schools.

ECCE is a right recognized in the Convention on the Rights of the Child. It improves the well-being of young children especially in the developing world where poverty is rife and child mortality rates high. It acknowledges that early childhood is a time of remarkable brain development with a high potential for learning. ECCE contributes to other EFA goals in relation to preparing a child for entry into primary school and reducing the levels of non-completion and repetition of grades in primary school.

In recent years, many countries in the Asia-Pacific region have increased attention to early childhood development through policy reviews and through conducting research (see Rao \& Pearson, 2008a, 2008b). Clearly there has been considerable momentum in early childhood policy in many countries in Asia including Cambodia.

Against this background, this paper (i) provides an 
overview of national statistics related to the health and development of young Cambodian children and their access to ECCE programs; (ii) analyses government policy, administrative structures, and funding for ECCE; (iii) discusses the different models of preschool provision; and (iv) considers the implications of recent initiatives and research findings for government policy and children's well-being.

\section{Health, Development and Access to Early Childhood Programs}

The ability of children to learn is directly related to their health status and in a country as poor as Cambodia improvements in education and learning opportunities cannot occur without concomitant improvements in health and nutrition.

\section{Infant and Child Mortality}

Over a quarter of Cambodia's population (projected to be 14 million) are aged nine or less. The 2000 and 2005 Cambodian Demographic Health Surveys (Royal Government of Cambodia [RGOC], 2003, 2005) indicated continuing high infant and under-five mortality rates. In 2007, infant and underfive mortality rates were 70 and $91^{1}$, respectively (UNICEF, 2008). Despite a decline in infant and child mortality in recent years, they remain the highest in the East Asia and Pacific Region. Furthermore there are significant differences between the infant mortality rates of families in the poorest and richest economic quintiles; 110 compared with 50 as of 2000 (UNICEF \& RGOC, 2006). The major causes of death are diarrhea, pneumonia and neonatal disorders.

\section{Failure to Thrive}

About $14 \%$ of children are born with low birth weight (UNICEF, 2008), the consequence of malnourished, underweight mothers giving birth to underweight babies. Only $69 \%$ of mothers receive any ante-natal care at all and the maternal mortality rate is very high (470 deaths per 100,000 live births) (UNICEF, 2008). Malnutrition significantly contributes to early childhood mortality and morbidity and it is estimated that $54 \%$ of childhood deaths are associated with insufficient food. This is exacerbated by micronutrient malnutrition, particularly the lack of vitamin $\mathrm{A}$, iodine and iron which are all essential for healthy growth and development. In addition, Cambodia has high rates of stunting (low height for age), wasting (low weight for age) and underweight children (less severe low weight for age). About $37 \%$ of children have been stunted and their development compromised by the age of five. About $7 \%$ of children suffer from severe malnutrition and $36 \%$ from moderate malnutrition (UNICEF, 2008).

Growth falters typically around six months of age which is when breast feeding mothers begin to introduce complementary foods that may be inadequate, inappropriate and unhygienically prepared. The government lists the causes of malnutrition as multiple including: disease, inadequate food intake, poor caring practices, lack of access to health and basic services including safe water and sanitation, and poverty. They also comment that caretakers' level of education and knowledge concerning the care of children is a significant factor.

\section{Improvements in Health}

As a result of intensive immunization efforts the number of measles cases was reduced by $97 \%$ between 2000 and 2004. Cambodia has been polio free since 1997 and vitamin A prophylaxis increased from $57 \%$ in 2000 to $70 \%$ in 2004. The Cambodian government issued a sub-decree on the iodization of all edible salt in 2003 and a salt producers' association was formed in 2004 leading to a rapid increase in the production of iodized salt to meet the full national requirement in 2004. The number of health centers providing a minimum package of health care services has increased from 386 in 1998 to 833 in 2004 . We are beginning to see drops in diseases such as measles and neonatal tetanus which are associated with 
decreasing infant and child mortality rates (RGOC, 2005).

\section{Participation in ECCE Programs}

In 2000-01 about $6 \%$ of three to five-year-olds of an estimated population age cohort of 957,193 were receiving organized preschool services. By June 2001 this had increased to $8 \%$ of an age cohort of $1,004,001$ and included children in nonpublic facilities (RGOC, 2003). In 2005-06, the enrolment rate in ECCE was $11.97 \%$.

Figure 1 illustrates this trend and shows the number of children enrolled in ECCE in urban, rural and remote areas. As about $80 \%$ of Cambodia's population lives in rural areas, we can expect higher enrolment rates in rural areas.
In 2005-06, there were 75,669 children enrolled in State Preschools (SPS), 22,265 children in Community Preschools (CPS), 7,181 children in Home-based Programs (HBP) and 8,512 children in private preschools. There has been a marked increase in enrolment in all types of programs since 2004-05. Table 1 illustrates the differences in Gross Enrolment Rates between the three types of programs. There is some inconsistency in the reported current numbers of children enrolled in preschool programs. As mentioned earlier, the enrolment rate for three to five- year-olds was $11.97 \%$ in $2005-06$ by the Ministry of Education, Youth and Sports (MoEYS). However, another report by the MoEYS puts it at 13.6\% (Department of Early Childhood Education, 2006). This is the only source of information on

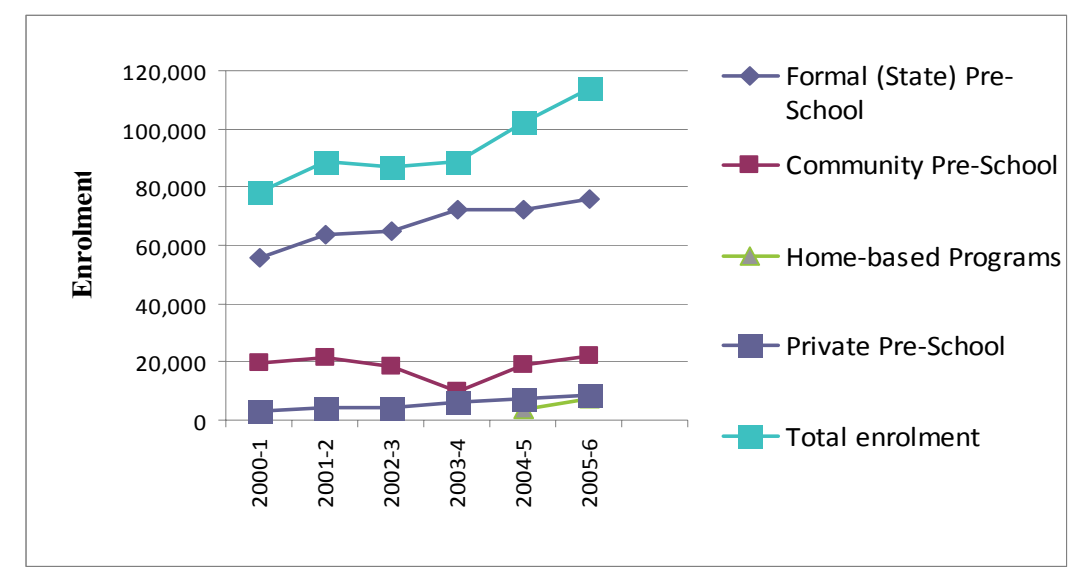

Figure 1. Enrolment in Early Childhood Care and Education programs

Table 1.

Enrolment Rates in Preschool Programs for 3- to 6-year olds

\begin{tabular}{ccccccccccc}
\hline \multicolumn{10}{c}{ Types of Preschool Programs } \\
\hline & \multicolumn{1}{c}{ SPS } & \multicolumn{1}{c}{ Private Preschool } & \multicolumn{2}{c}{ CPS } & \multicolumn{2}{c}{ HBP } & \multicolumn{2}{c}{ Total } \\
\cline { 2 - 13 } & $2004-05$ & $2005-06$ & $2004-05$ & $2005-06$ & $2004-05$ & $2005-06$ & $2004-05$ & $2005-06$ & $2004-05$ & $2005-06$ \\
\hline 3-5 years & 7.65 & 8.59 & 0.58 & 0.96 & 1.98 & 2.52 & 0.59 & 1.52 & 10.89 & 13.60 \\
\hline 5-6 years & 17.97 & 21.23 & 4.98 & 1.43 & 0.40 & 3.96 & 1.28 & 0.84 & 24.56 & 27.27 \\
\hline
\end{tabular}

Note. From ECCE report for Education Congress (End Year Report) 


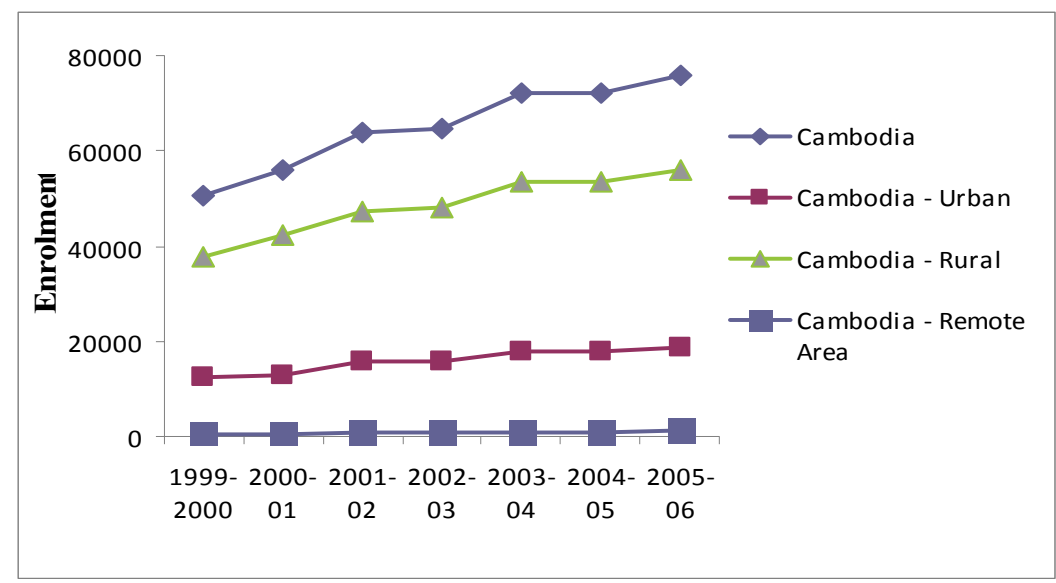

Note. From MoEYS Education Management Information System

Figure 2. Changes in Enrolments in State Preschools over Time

Table 2.

A Comparison among State Preschools, Community Preschools and Home-based Programs

\begin{tabular}{|c|c|c|c|}
\hline & State Preschools & Community Preschools & Home-Based Programs \\
\hline Year started & Before 2000 & 2004 & 2004 \\
\hline Age range of children & 3-6 years(3 classes L1-L3) & $3-5$ years & Birth to 6 years \\
\hline $\begin{array}{l}\text { Number of children } \\
\text { covered in } 20052006\end{array}$ & 75,669 & 22,265 & 7,181 \\
\hline $\begin{array}{l}\text { Hours per day/week } \\
\text { Weeks per year }\end{array}$ & $\begin{array}{l}3 \text { hours per day/ } \\
5 \text { days a week } \\
38 \text { weeks/year }\end{array}$ & $\begin{array}{l}2 \text { hours per day/ } 5 \text { days a } \\
\text { week } \\
24-36 \text { weeks/year }\end{array}$ & $\begin{array}{l}\text { Mother groups and the } \\
\text { children typically meet } \\
\text { once a week but this varies } \\
\text { across projects } \\
24 \text { weeks/year }\end{array}$ \\
\hline Establishment & $\begin{array}{l}\text { Responsibility of the } \\
\text { MoEYS }\end{array}$ & $\begin{array}{l}\text { Responsibility of } \\
\text { Commune Councils }\end{array}$ & $\begin{array}{l}\text { Responsibility of } \\
\text { Commune Councils }\end{array}$ \\
\hline Curriculum & $\begin{array}{l}\text { MoEYS } \\
\text { to be aligned with the } \\
\text { ELDS }\end{array}$ & $\begin{array}{l}\text { MoEYS } \\
\text { to be aligned with the } \\
\text { ELDS }\end{array}$ & $\begin{array}{l}\text { MoEYS } \\
\text { to be aligned with the } \\
\text { ELDS }\end{array}$ \\
\hline Staffing & $\begin{array}{l}\text { A teacher who has } \\
\text { undergone professional } \\
\text { training }\end{array}$ & $\begin{array}{l}\text { A locally recruited and } \\
\text { trained teacher }\end{array}$ & $\begin{array}{l}\text { Mothers led by a "core" } \\
\text { mother }\end{array}$ \\
\hline Staff Training & $\begin{array}{l}\text { A 2-year full-time teacher } \\
\text { training course after } \\
\text { Grade } 12\end{array}$ & $\begin{array}{l}\text { Initial training for } 10 \text { days } \\
\text { Annual refresher training } \\
\text { for up to } 6 \text { days a year }\end{array}$ & $\begin{array}{l}\text { Refresher training for } 6 \\
\text { days a year }\end{array}$ \\
\hline Salary/Incentives & $\begin{array}{l}\text { MoEYS } \\
\text { Monthly salary of USD } 20\end{array}$ & $\begin{array}{l}\text { Teacher incentive of USD } \\
7.5 \text { per month }\end{array}$ & Not Applicable \\
\hline
\end{tabular}


enrolment rates for children between 5 and 6 years According to this report, the enrolment rates for 5- to 6-year-olds in $2005-06$ was $27.27 \%$ (79,454 children including 39,884 girls), which represents an increase from $24.56 \%$ in $2004-05$.

Figure 2 shows gross enrolment rates in State Preschools. However, almost no children are enrolled in early education in the remote areas. This is a concern as children living in these areas may have multiple disadvantages, such as, poverty, poorly educated mothers and ethnic minority status. The timings and the months of operation of the CPS and HBP take into account the fact that many parents are farmers. For example, the CPS program finishes at 9.00 a.m. and the CPS and HBP do not operate in the harvest seasons. The child is taken care by the mother/other family members after school hours. As shown in Table 2, there are considerable differences among the three programs in their dates of establishment, size and modes of operation. These differences clearly affect program quality.

Tuition is free in all three types of ECCE programs, i.e., parents pay nothing. In the SPS, teacher salary is paid by the government and teachers in the CPS receive a token remuneration paid by UNICEF/ NGOs and the local commune council. Mothers in the HBP do not receive any incentives.

Very few alternatives or provisions for children under 3 years exist. It is probably safe to conclude that there has been a considerable increase in provision over the last decade (bearing in mind that it started from a very low base figure) and that currently about $12 \%$ of children between three and five years receive some form of ECCE.

\section{Policy, Administrative structures, and Funding}

\section{Goals and Principles}

In its 2003 National Plan, the Cambodian government articulated the following goals of ECCE: (i) to enhance survival, growth and development status of all Cambodian children; (ii) to enhance all Cambodian children from birth to school entry to benefit from improved care so that they may achieve optimal physical and psychosocial development both at home and through participation in integrated and inclusive community-based health, hygiene, nutrition, development and early education programs of good quality; and (iii) to enhance readiness of all Cambodian children to begin school at 6 (RGOC, 2003).

However, the Cambodian EFA Assessment Report (2000) commented that progress towards these goals had been slow, especially in the area of ECCE. However the EFA Mid-Decade Assessment noted progress in enrolment and efforts to enhance the quality of programs (UNESCO, 2008). Programs for children between birth and 3 years are scanty and undefined.

The government also outlined six guiding principles within which these goals must be achieved (RGOC, 2003). These include low cost, inclusivity, readiness, efficiency, equity and integration. Such principles are common in almost all countries.

\section{The Inter-Ministerial Approach}

As stated earlier, ECCE has to adopt a holistic approach to the child and include components of health, nutrition and care as well as education. All have an impact on learning outcomes. Such an approach cannot be achieved by one government ministry alone and requires sophisticated coordination to design and implement successful strategies (RGOC, 2003), particularly in relation to the psychosocial development milestones which the Cambodian government has identified as currently lacking (RGOC, 2003). In recognition of this, an Integrated Childhood Development Sub-committee of the Cambodian National Council for Children was formed to facilitate, monitor and co-ordinate actions of all ministries responsible for implementing child health, growth and development activities.

Key partners in the provision of ECCE are the 
Ministry of Health, the Ministry of Women's Affairs, NGOs, Parents Associations and community groups, and the MoEYS which functions as the lead ministry. A Department of Early Childhood Education has been formed under the Ministry of Education, Youth and Sports but its role was largely confined to managing existing preschools. However it now also provides technical inputs to enhance the quality of CPS and HBP (RGOC, 2003).

Unless increased resources are available to it, the Department will not be able to expand ECCE to meet government targets. One of the issues that must be recognized and addressed is the lack of horizontal integration between different ministries and departments who tend to act in isolation from one another even when dealing with the same program. Building effective integrative structures will be essential but very challenging.

\section{Proposed Provision}

The Cambodian government has recognized that current preschool is "too little, too late", for the vast majority of three to five-year-old Cambodians. The broad policy target will be to increase the net enrolment into ECCE of five-year-olds to $50 \%$ by 2010 and $75 \%$ by 2015 (RGOC, 2003). The government does not envisage a downward expansion of the primary school cycle of six years to include pre-primary education for five-year-olds. This target is to be achieved through the provision of home-based, playgroup style programs, community/centre based programs and school based programs. However, there are already signs that this target will not be reached. At least according to one report, between school years 2003-2004 and 2005-2006 the numbers of children attending ECCE activities increased by only $2.18 \%$, reaching a total of $21.32 \%$ in $2005-2006$ (UNICEF \& PoE, 2007). It seems unlikely that provision will increase by the necessary $28 \%$ in the next four years.

\section{Responsibility for Implementation}

The MoEYS focuses on curriculum development and materials, staff development and quality assurance. It has no responsibility for direct service provision and as part of the policy of decentralization, the Department of Early Childhood Education, while acting as a catalyst, also does not implement services directly (other than the state run preschools). The provision of services has been left to NGOs, parents, community workers and particularly Commune Councils at the local level. The assumption is that having a deep understanding of local needs and culture they will be able to choose and finance models most appropriate for their locality. The Department of Early Childhood Education has been active, in conjunction with UNICEF, in developing training teams in each province for improving the quality of newly evolved community preschools. Training focuses on thematic learning and the development of weekly activity plans. Learning objectives are linked to the child's domains of development appropriate to age: physical (gross/fine), motor, sensory, cognitive, language, emotional/aesthetic, social and personal development.

\section{Funding Mechanisms}

This perception of ECCE as a responsibility of each locality has funding implications. It is noticeable that while the government is prepared to commit itself to central funding of primary education it states clearly that it cannot make the same commitment to ECCE. Thus villages are expected to find their own resources supplemented by NGO and donor partners "to evolve new approaches that will lead to universal preschooling but without reliance on the scarce budgetary resources of the MoEYS". The exception is in poorer areas where it is accepted that "public funding of high-quality, community programs of integrated childcare will be necessary for some time to come" (National Report, 2003, p. 29). Parental, private and community contributions are expected to 
lead to the achievement of $75 \%$ non-government funding of ECCE programs by 2014.

The funding model proposed is not without problems. It has been pointed out that the decision to encourage community and private sector funding for the provision of preschool services risks leaving poorer communities with restricted access, thus perpetuating the cycle of inadequate school preparation, class repetition, eventual drop-out and adult illiteracy. The MoEYS has said that they cannot afford to increase the amount they currently spend on preschooling most of which benefits the wealthier sectors of society. The safety net for poor children will consist of re-directing the money currently spent to deprived areas. The assumption is that parents in the wealthier, urban areas will be left to fund provision for their children. Whether this will be enough to achieve the extensive goals of ECCE in a country where the majority of children live in severe poverty is debatable.

It is worth noting that at the Fifth E9 Ministerial Meeting on ECCE that took place in Cairo in 2003 it was stated quite clearly that ECCE cannot be achieved through a community mobilization strategy alone (UNESCO, 2003). They point out that it is already difficult to persuade the relevant ministries at central government level of the importance of giving priority to pre-primary services. It is even harder to ensure that local authorities and townships allocate sufficient money out of what must already be a restricted and over-stretched budget. They suggest that delivery and management of services at a local level is appropriate but that sufficient funding has to come from the central government and to suppose otherwise is a sign of naivety or insufficient commitment to ECCE.

\section{Inclusion and Equity}

It is clear from government statements (see earlier) that their formal policies espouse education for all children. None are to be excluded on the grounds of gender, poverty, disability or ethnic minority status, or, indeed, for any other reason. These statements are made within the framework of acceptance of the human rights of the child and cross-cut all aspects of Education for All policies. However, overcoming discrimination against such groups is a highly complex matter involving not only money, which is at least straightforward, but centuries of cultural attitudes and belief, which are not. An examination of the formal documents (RGOC, 2003; UNICEF \& RGOC, 2006) shows that the two groups most frequently mentioned as being excluded are children in poverty and girls. Children with disabilities and ethnic minorities are much less frequently identified. The broad policy thrust is to reduce the cost barriers to access to high quality basic education for all through a combination of systemic developments (like abolishing informal payments) and targeted interventions (incentives for the poor, girls and ethnic minorities) to attend school (RGOC, 2003). For instance, in 2001 the abolition of start of year parental contributions for Grades 1 to 6 contributed to an increased primary school enrolment from 2.35 million to 2.68 million in twelve months (RGOC, 2003).

Exclusion on the grounds of gender. The numbers of girls and boys in preschool are more or less equal. However, that involves only about $20 \%$ of the relevant age cohort. In school year 2004-2005 the enrolment rates in primary school were $91 \%$ for girls and $93 \%$ for boys. In 2001-2002 the enrolment rates were $84 \%$ and $90 \%$, respectively. Improvements in enrolment rates were seen most amongst girls and boys from the poorest economic quintile. The picture becomes gloomier the further up the education ladder one goes. At lower secondary level $37 \%$ of students are girls; at upper secondary level, $32 \%$ and very few girls complete secondary school.

The traditional role expectations on school age girls function to keep them out of school because they are expected to perform household chores and childcare (thus enabling their mother to participate in a wage economy) or take on household income generation 
activities themselves (RGOC, 2003). The introduction of garment manufacturing, taking advantage of lax labor laws and cheap female labor, has provided an income earning opportunity for young girls that may keep them out of school.

Exclusion on the grounds of poverty. No one is more likely than a child to live in poverty in Cambodia (UNICEF \& RGOC, 2006). The representation of the poor is much greater in the primary than in the secondary or tertiary student population. In Cambodia $20 \%$ of primary students but only $2 \%$ of upper secondary students are drawn from the poorest $20 \%$ of the population. In contrast, $61 \%$ of the upper secondary students come from the richest $20 \%$ of the population. The representation of the poor in tertiary education is zero whilst the richest $20 \%$ account for $57 \%$ of tertiary level students. As has already been discussed, poor children are currently rarely found in preschool provision and the MoEYS has identified them as a target group on which to spend its limited resources for ECCE in order to ensure equity of opportunity. It acknowledges that this is likely to be challenging as the poorest communities lack good models, infrastructure and experienced providers.

Exclusion on the grounds of disability and ethnic minority status. The National Plan (RGOC, 2003, p.40) states in the case of children with disabilities that national policy and strategies should be formulated "to assure equitable access to education opportunities including specific program interventions such as school buildings design, specialized teaching and learning materials". With regard to ethnic minorities it says that targeted facilities, programs and curriculum reform should be provided, with special incentives for minority area staff deployment as well as the hiring of local teachers. There is a suggestion that inclusion in the life of the community can be pursued through access to education and that this is therefore a priority for the government. However, little detailed information is given about how this can realistically be achieved. UNICEF has been involved in starting the first preschool for deaf children in Cambodia in 2004, located in Krousar Thmey. The goal was to teach children sign language so that they had a language with which to communicate when they entered primary school. The project has created a Khmer Braille code and set up a committee to work on creating a uniform Khmer sign language.

The Department of Early Childhood Education (2006) reported that three staff had participated in training for the education of children with special needs (i.e., with a disability or from ethnic minorities) for 14 days with International Cooperation Cambodia (ICC). The department also developed materials for parents on early interventions for children with a disability. District Office of Education staff responsible for Early Child Development and core mothers from home based projects in the six UNICEF supported provinces have also been given training on disability in children.

As part of a study carried out for UNICEF on child rearing practices Covar (2006) asked questions about disability. It is notable that when his 196 respondents were asked whether children with a disability should go to school the majority (154) said they should not. When asked whether children with a disability should be treated differently to normal children 153 out of 199 respondents said they should not, but a significant minority (36) thought that they should. Covar concluded that there was an undercurrent of discrimination and lack of acceptance towards children with a disability.

\section{Early Childhood Provision}

This section examines how the policy on ECCE and preschooling has been developing in reality. Of particular importance is the principle of decentralization which pushes responsibilities down to the commune council levels and the decision that preschools should be funded locally, not centrally, except in areas of 
special hardship.

\section{State Preschools}

State preschools, which are typically located in primary schools, operate a 3-hour programme, 5 days a week during the 38-week school year. Classes are taught by a teacher who has completed a 2-year full-time professional preparation course undertaken after Grade 12. Rao and Pearson (2007) found that all stakeholders preferred the State Preschools to both the CPS and HBP because of their longer hours of operation, the formal training that teachers received and clear line of management from the MoEYS. They believed that the State Preschool system was well-established, well-managed and highly functional.

\section{Community Preschools}

In Community Preschool programmes, educational experiences for three to five-year-olds are provided by a member of the village who has typically received ten days of initial training and who participates in refresher training for three to six days a year. The programme operates for 2 hours a day, 5 days a week, for 24 to 36 weeks a year. The teaching methodology follows the same basic routine every day to give students a sense of predictability and security. Teachers, who are volunteers but receive a small stipend, are given training in areas related to health, nutrition and psychosocial early child development as well as various teaching methodologies. On-going training is encouraged through refresher courses, teachers meetings and the technical monitoring provided by staff from the MoEYS.

UNICEF assisted over 900 CPS in six provinces as part of Seth Koma, its Community Action for Child Rights Program. According to a report produced by the Department of Early Childhood Education 22,265 children attended community preschools in school year 2005-2006. Losert (2005) on behalf of UNICEF has produced a manual outlining all the administrative and funding procedures that should be followed in setting up a preschool, although it has nothing to say about curriculum issues. Of particular importance is the emphasis on involving all stakeholders, from Commune Council officials, to representatives of local Women and Children's Committees, to officials of local Departments of Education, parents and village chiefs and representatives. The manual outlines the needs of a preschool (e.g., suitable shelter, volunteer teacher, instructional materials, snacks for the children), monitoring procedures and standards, qualifications expected of what are described as "volunteer teachers who will be paid an incentive", the terms of the contract that such volunteers should sign, and the further training that should be provided. The overall objectives of the CPS are stated as improving Grade 1 school performance and age 6 enrolments and decreasing Grade 1 drop-out rates. Grade 1 students will be evaluated at the local primary school following the preschool year.

Challenges associated with the operation of CPS include the uncertainty of financial support to teachers, diminished support from the villagers for CPS after the initial enthusiasm; and having classes under teachers' houses. Such settings posed problems in terms of hygiene, lack of clean water and sanitation, and nowhere for children to play. In such circumstances some parents were afraid to send their children to school. Further, some government officials and villagers lacked faith in the sustainability of the CPS program and villagers tended to send all their children, including those less than three years of age, to the CPS, making the job of the teachers very difficult.

\section{Home-based Programs}

Home-based programmes provide educational resources and opportunities for mothers to come together weekly as a group, led by a trained "core" mother, who provides instruction on how to promote children's development and well-being. Meetings of mothers groups and their children are typically held for one hour a week for 24 weeks a year. In the 2003 
National Plan (RGOC, 2003) home based programs were envisaged as an important part of the structure of ECCE but were not well-conceptualized, other than to be described as 'play groups'. While the MoEYS, with UNICEF support, has recently developed and distributed a calendar of prescribed activities for the HBP, there seems to be a lack of formal documents about home based preschooling. This is different to the situation described above for CPS. So far, however, home based preschools reach only a small number of children; 13,447 of whom 6,770 are female in school year 2005-2006, although this is an increase of 7,893 (58.69\%) over school year 2004-2005 (Department of Early Childhood Education, 2006). So, for the moment at least, home based preschools are the fastest growing sector, albeit they represent a small proportion of the total pre-school provision.

HBP programs are supported by several NGOs and tend to adopt slightly different models depending on the funding agency. However, they all tend to emphasize developing basic education competencies using local contexts, resources and parents' own skills and capacities. Part of the program involves working with parents to help them understand how they could help their children to learn and assisting them to design child development activities that are comprehensive, holistic and culture-specific. For example mothers are encouraged to maintain a loving, caring, safe and secure environment, to promote routine health habits, engage with their children during home-life activities, engage their children in activities such as story-telling, visits to the market, special events and celebrations.

In addition to activities around the home, activity sessions for mothers and their children are conducted by a preschool teacher and held at a home-based centre. Although 'parents' are the formal targets the key player is almost always the mother. Within the project "core" mothers were identified as women with more experience, selected by villagers, but from the same villages and socio-economic circumstances as the other mothers. They receive training from preschool and primary teachers and attend monthly meetings where they are given hand-outs and handson practice with children in homes, peer support and co-operative problem solving. They were also given "justifications" as to why some interventions were better or worse than others so they developed a

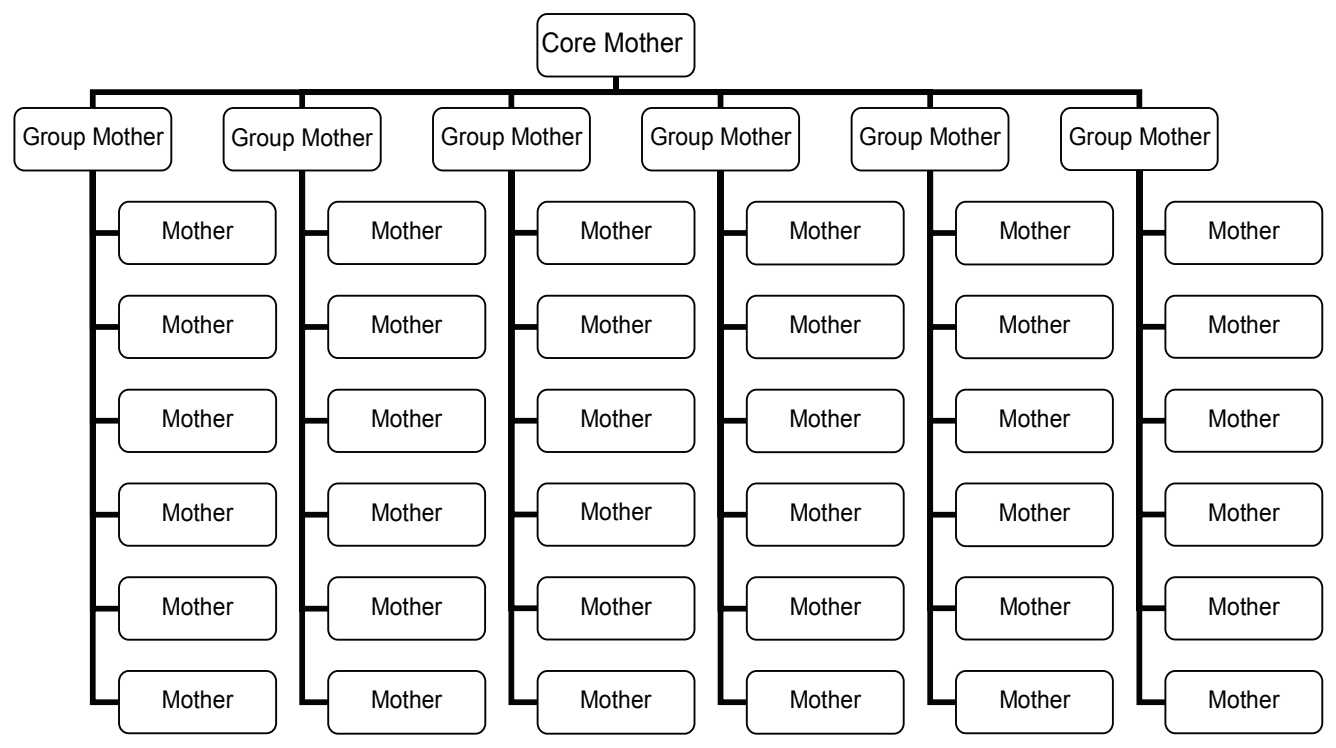

Figure 3. The organization of Mother Groups in the Home-based programs 
theoretical understanding of the reasons behind preferred actions. Core Mothers lead groups of mothers.

Figure 3 illustrates the organization of the Homebased programs. The program as it is operating now has a core mother and Group mothers who assist the core mother in working with the groups. The Group mother is herself a mother with a young child and a beneficiary of the program. The advantage of this program is that it requires little money to run and the capital costs are zero. It is thus replicable in other poor, isolated and remote communities. It also establishes networks of information and support between mothers and between villages and government officials from the Provincial and District Education Offices. Simple games, lessons and learning activities can be developed using materials and resources easily available in the village.

A large number of children who would otherwise have had no access to preschooling of any sort have been reached by HBP. Participation is typically an empowering experience for mothers who have acquired new skills themselves and been able to pass them on to other mothers in their villages, introducing them to the idea of children's rights and the need for Education for All at the same time.

However, there have been constraints. Insufficient supplies are provided for the Mothers' Groups as storage is a problem; the classes are generally held under the core mothers' homes in less than ideal circumstances; core mothers' are inexperienced volunteers whose teaching skills are limited by lack of training; no stipends or incentives are provided and ways need to be found to encourage greater community participation in and ownership of the outcomes of childcare and learning activities.

It is obvious from these examples that much can be achieved without a large infusion of outside funds. But it is equally obvious that without some additional funding such projects are unstable. In addition the reliance on volunteers who already have many demands on their time as wives, mothers and farmers with no recompense is almost certainly a limiting factor. It also remains to be seen how effective these home based projects are in preparing children for school and for preventing high dropout rates. Evidence from India suggests that even quite basic preschool programs that are not well resourced by international standards can achieve a great deal (Rao \& $\mathrm{Li}$, 2007). Unless the local community is able to own and sustain that momentum, the future for such HBP may not be rosy.

\section{Preschool and Preparation for Primary School}

It is widely accepted that preschool experiences, by preparing the child academically and socially for school, lowers repetition and drop-out rates. The benefit is felt most by children in the poorest communities. Yet in Cambodia, children with the greatest need of the chance to learn in groups, mix with others, acquire pre-academic and language skills before they begin primary school are the ones that have the least access. Thus ECCE is not only intrinsically important but is needed to provide experiences and preparation that gives a child a much better chance of succeeding in school and completing at least six years of primary school. ECCE is a vital component of a successful Education for All strategy.

Although the initial enrolment in primary school has improved significantly, the drop-out rate remains stubbornly high and one of the main reasons is poverty. Families are often unable to pay the cost of schooling that can amount to $79 \%$ of per capita nonfood expenditure of the poorest $20 \%$ of families. Another significant concern regarding children in Cambodia is that at the formal age of enrolment into primary school, many are too immature in their physical, social, linguistic and cognitive development. This is reflected in delayed enrolment and high repetition rates in Grade 1 leading to high dropout rates (RGOC, 2003). They are simply not ready for school as a result of malnutrition and lack of preschool experiences. Only 58\% of Grade 1 students are six years old, the prescribed school entry age. 
Only $45 \%$ of children in Cambodia who start primary school will complete Grade 6, and only 38\% will enter lower secondary school. It takes an average of 10.8 years for a child to complete the six-year primary school cycle (UNICEF \& RGOC, 2006).

\section{Recent Initiatives}

Three relatively recent projects have the potential to impact on child care and educational policy and practice in Cambodia. The first one, the School Readiness Program, was designed to compensate for children's lack of access to ECCE programs prior to school entry while the second one, the School Readiness Standards, aimed to enhance children's readiness for primary school. The third project was commissioned by UNICEF Cambodia to examine the effectiveness of different ECCE programs in promoting children's preparedness for school. It also considered issues related to the scaling up of CPS and HBP for 5-year-olds. Each of these will be considered briefly.

\section{School Readiness Program}

The MoEYS developed and implemented a very successful School Readiness program. This 8-week program, which was established in 2004-05 and designed for children who had no preschool experience, was offered at the beginning of Grade 1 in primary schools. The goal of the program is to reduce the high rates of primary school repetition and drop out and increase student achievement. Evaluations indicate that the program has been successful in meeting its objectives. Children who participated in the School Readiness Program had significantly better immediate acquisition of school readiness skills and longer term school achievement (Nonoyama-Tarumi \& Bredenberg, 2009) and were less likely to drop out of school than a comparable group of children who did not participate in the program (Department of Early Childhood Education, 2006). The program has now been expanded to cover a longer period in Grade 1.

\section{School Readiness Standards}

Another relatively recent development in Cambodia that has implications for the curriculum and instruction in ECCE programs is the development of the Cambodian School Readiness Standards. These fall into the following 5 domains: Physical and Health Development; Moral and Cultural Development; Social and Emotional Development; Cognition and Reasoning; and Language Development (see Miyahara \& Meyers, 2008). The MoEYS is responsible for documents and curriculum for all ECCE programs and it is currently revising the curriculum for all ECCE programs so that it will be aligned with the School Readiness Standards, which were finalized in August 2007. Hence, all fiveyear-olds in Cambodia, regardless of whether they attend the SPS, CPS or HBP will shortly have access to the same basic curriculum.

\section{Evaluation of Early Childhood Care and Education Programs}

Rao, Pearson, Constas and Pearson (2007) evaluated a range of Early Childhood Care and Education (ECCE) programs in Cambodia in order to recommend strategies to enhance their effectiveness, sustainability and expansion. Using stratified random sampling, children who had attended State Preschools (SPS), Community Preschools (CPS), Home-based Programs (HPS) or no programs (control group) were selected and compared on developmental functioning. Participants were 1,312 children (668 girls) from all six UNICEF-supported provinces in Cambodia. Children's developmental functioning was assessed twice, one year before and just before Grade 1. In all provinces, the SPS, CPS and HBP were systematically observed and evaluated. Stakeholders (government officials, commune council members, parents and teachers) were also interviewed. Results indicated that: (i) Children in programs had significantly better 
developmental functioning than those in the control group. Children in SPS had the highest functioning and there were no significant differences between children in CPS and HBP; (ii) Maternal education, geographical location and enrolment in ECCE programs interacted to influence children's development; (iii) ECCE quality was dependent on teachers' characteristics, which varied considerably across programs; and (iv) All stakeholders expressed support for ECCE but officials mentioned concerns about their sustainability and problems with program monitoring were noted.

\section{Conclusions and Implications}

EFA policies at the central level unequivocally support the need for ECCE as a means to improve the health, well-being and school readiness of children below six years. These policies are framed to be inclusive of all disadvantaged children, particularly those in extreme poverty, girls, children with a disability and those from ethnic minorities. At the moment, Cambodian children have some of the worst health indices in the East Asia and Pacific region, including stunting and severe malnutrition as well as high mortality rates. The government accepts that children who are underfed and understimulated are unlikely to make the transition to Grade 1 in primary school successfully. This accounts for the very high levels of drop-outs and grade repetitions that are common in Cambodia. On average it takes 10.8 years for a child to complete six years of primary school.

In school year 1998-1999 only around 6\% of children received any preschooling. In school year 2005-2006 it was estimated to be $11.97 \%$ for children between three and five years and $27 \%$ for children between five and six years. The government's target is to ensure that $50 \%$ of all 3-5 year olds are in some kind of preschool by 2010, a figure they wish to increase to $75 \%$ by 2014. Preschooling includes HBP, CPS and SPS which are typically attached to primary schools. The organization is perceived to require a multiplicity of stakeholders involving many government ministries as well as NGOs, Commune Councils, villagers and parents. Funding is an issue. Whereas the government accepts responsibility for funding free primary school education for all, it anticipates that most of the funding for preschools will have to be generated locally. The only funding responsibility that it accepts is for those children from the very poorest communities. This will not increase the central budget for preschool as the government intends shifting its funding from formal state preschools (attached to primary schools) to the poorest sector. Parents with children in formal state preschools will be expected to pay for their child's preschooling. While much has been written in various reports about bureaucratic procedures concerning the structures of formal organizations involved in providing preschooling, funding models and monitoring procedures, very little emphasis has been given to the integration of health improvement strategies (like state funded supplementary feeding programs) into preschooling contexts. It is only recently that attention has been directed to the curriculum of ECCE programs.

There are a number of successful models of preschools, often supported by major international NGOs (e.g., UNICEF and Save the Children Fund). They demonstrate that much can be achieved with simple facilities and basic resources in the villages. However, they tend to report the same problems regarding lack of funds, unqualified/untrained teachers and difficulties in sustaining momentum. Some also identified that parents and villagers were not wholly in sympathy with some of the goals and strategies of preschooling which contradicted traditional beliefs.

If the momentum generated by the identification at the national level of ECCE as an important foundation for education is to be sustained, it is vital to continue to generate demand for ECCE, increase access and enrolment by providing services close to 
where the child lives, enroll children in early childhood programs before they reach age four, enhance government and private funding of ECCE, encourage community involvement and participation in ECCE through the development and enactment of appropriate policies, focus of the quality of program, promulgate good practices, encourage coordination among stakeholders and demonstrate through properly conducted research that the programs being implemented are producing the desired outcomes.

\section{References}

Covar, P. R. (2006). Family care practices and child rearing in Cambodia: Final Report. Cambodia: UNICEF.

Department of Early Childhood Education. (2006). Final report on the early childhood education project, school year 2005-2006. Cambodia: Ministry of Education Youth and Sports.

Losert, L. (2005). Social service delivery by the Commune/Sangkats as part of the decentralization process of Cambodia: An example of community preschool provision. Cambodia: UNICEF.

Miyahara, J., \& Meyers, C. (2008). Early learning and development standards in East Asia and the Pacific: Experiences from eight countries. International Journal of Early Childhood, 40 (2), 1731.

Nonoyama-Tarumi, Y., \& Bredenberg, K. (2009). Impact of school readiness program interventions on children's learning in Cambodia. International Journal of Education Development, 29, 39-45.

Rao, N., \& Pearson, E. (2008a). Introduction to the special issue: Policy change in early childhood in the Asia Pacific region. International Journal of Early Childhood, 40 (2), 7-10.

Rao, N., \& Pearson, V. (2008b). Transforming early childhood care and education in the Insular South East Asia and Mekong sub-regions: Implications of the global monitoring report 2007. Bangkok, Thailand: UNESCO Bangkok.

Rao, N., Pearson, E., Constas, M.A., \& Pearson, V. (2007). Evaluation of community preschool and homebased early childhood programs in Cambodia. UNICEF: Cambodia.

Rao, N., \& H. Li. (2007). The influence of preschool programs on children from socially disadvantaged backgrounds in India. Paper presented at the biennial meeting of the Society for Research in Child Development Conference, Boston, USA.

Royal Government of Cambodia (2003). Education for all: National plan, 2003-2014. Cambodia: Author.

Royal Government of Cambodia (2005). Cambodian demographic health survey. Cambodia: Author.

UNICEF., \& Provincial Office of Education. (2007). Oddar Meanchey province report on early childhood education, school year 2005-2006. Cambodia: UNICEF.

UNICEF., \& Royal Government of Cambodia (2006). Country programme action plan 2006-2010. Cambodia: UNICEF.

UNICEF. (2008). The state of the world's children 2009. New York: Author.

UNESCO. (2000). The Dakar framework for action: Education for all, meeting our collective commitments. Paris: Author.

UNESCO. (2003). Early childhood care and education in E-9 countries: Status and outlook. Paris: Author.

UNESCO. (2008). Asia and the Pacific education for all (EFA) mid-decade assessment: Mekong sub-region synthesis report. Bangkok, Thailand: UNESCO Bangkok.

1. Infant and under-five mortality rates are expressed per 1000 live births 